\title{
The Effect of the Operation Time, Orientation of Passenger and Body Mass Index on Passengers' Whole-Body Vibration on Urban Rail
}

\author{
Muhammad Nur Annuar Mohd Yunos*, Mohd Azlis Sani Md Jalil, \\ Nor Azali Azmir and Mifzal Nazhan Mazlan
}

Faculty of Mechanical and Manufacturing Engineering, Universiti Tun Hussein Onn Malaysia, 86400 Batu Pahat, Johor, Malaysia

\begin{abstract}
Urban rail is a widely used public transportation; the vibration from frequent rides may impact passengers. The rail vehicle's vibrations can cause human fatigue and result in severe musculoskeletal problems to the passenger. This paper aims to identify the effects of passenger orientation, operation time and body mass index on passengers' whole-body vibration on an urban rail in Malaysia. Real-time monitoring of the whole-body vibration was conducted using $2^{3}$ full factorial designs of the experiment, which was analysed statistically using Minitab Software. The overall result of this study is that the passengers in a seated position had greater exposure to whole-body vibration, which is $0.3686 \mathrm{~ms}^{-2}$ than standing passengers, $0.2965 \mathrm{~ms}^{-2}$. Also, passengers tend to be exposed to greater vibration during an off-peak time of $0.4063 \mathrm{~ms}^{-2}$, than a peak time of $0.3706 \mathrm{~ms}^{-2}$. Lastly, overweight passengers were exposed to greater vibration, of $0.4063 \mathrm{~ms}^{-2}$, than passengers within the ideal weight range of $0.4000 \mathrm{~ms}^{-2}$. This study has statistically proven that all the factors were significantly influenced the vibration exposure to the passenger. The most significant factor towards the vibration exposure is the "Body Mass Index (BMI)", in which the p-value is less than 0.001 . This study concludes that the whole-body vibration of

ARTICLE INFO

Article history:

Received: 26 March 2021

Accepted: 05 July 2021

Published: 08 October 2021 a passenger is affected by the orientation of the passenger, operation time and body mass index of passengers on urban rail service.
\end{abstract}

DOI: https://doi.org/10.47836/pjst.29.4.13

$\overline{\text { E-mail addresses: }}$

muhdnurannuar@gmail.com (Muhammad Nur Annuar Mohd Yunos)

azlis@uthm.edu.my (Mohd Azlis Sani Md Jalil)

azali@uthm.edu.my (Nor Azali Azmir)

mifzalnazhan7@gmail.com (Mifzal Nazhan Mazlan)

* Corresponding author
Keywords: Human factors, public transportation, rail ergonomics, ride comfort, whole-body vibration 


\section{INTRODUCTION}

In the era of globalisation, railway systems have become one of the most important public transportation; it is the main mode of transportation chosen by people, notably in highly developed countries (Ismail et al., 2010). Light Rail Transit (LRT) is the preferable mode of transport, especially in urban areas, as it is sustainable, improves travel options and facilitates swift mobility (Fateh et al., 2016). However, passenger comfort has become one of the essential factors in the competition with other modes of transportation (Dumitriu, 2013). Therefore, passenger comfort has become a priority among train operators. Based on previous researches, one of the major factors that affect passenger comfort level in trains is the vibration and vibration behaviour of the vehicle (Kim et al., 2009; Munawir et al., 2017). Not only vibration reduces the quality of the ride experience of the passenger, but it also affects the passenger's health (Zhou et al., 2016).

Passengers tend to experience health problems such as lower back pain with prolonged exposure to high-magnitude vibration caused by the trains (Nuawi et al., 2011). Vibration can also cause human fatigue and may result in severe musculoskeletal problems to the passenger (Mohajer et al., 2017). In trains, vibration is transmitted to the passengers through the floor, seats and backrests (Kumara et al., 2013).

\section{Whole-body Vibration (WBV)}

Whole-body vibration (WBV) is defined as the situation where the whole body experiences the effect of vibration when supported by a vibrating surface (Azlis-Sani et al., 2015). WBV can be transmitted to the whole body of the passenger through seats, backrests and the floor of the vehicle (Munawir et al., 2017). It can also be transmitted by standing and sitting in the vehicle (Smith et al., 2005). The effects of the whole-body vibration depended on the position of the passenger's body inside the train (Griffin \& Erdreich, 1991). Therefore, WBV was considered an important factor in passenger comfort as it is largely produced in the railway vehicle (Kim et al., 2009).

In the last two decades, a few major problems were found to occur in the human body due to exposure to whole-body vibration. Whole-body vibration increased the risk of having lower back pain and spine structural injury (Gągorowski, 2010; Schwarze et al., 1998). Some researchers have found that lower back pain due to whole-body vibration depended on the passenger's body mass index (BMI) because the spine supports most bodyweight (Mortimer et al., 2001; Pradhan et al., 2017).

Therefore, whole-body vibration should be measured to determine the value of vibration exposed to the passenger/driver inside the train. The whole-body vibration can be measured at three supporting surfaces: the seatback, the seat pan and the feet (Pradhan et al., 2017). The measurement procedure of whole-body vibration can be referred to in the international standard ISO 2631-1:1997 (Park et al., 2013). This measurement procedure can calculate whole-body vibration experienced by the passenger and crew in the railway industry. 
ISO 2631-1:1997 is a standard that focuses on mechanical vibration and mechanical shock. This standard provides the evaluation and analysis of the human exposure to whole-body vibration in relation to human health and comfort, the probability of vibration perception and the incidence of motion sickness (ISO, 1997). According to this standard, the frequency range, which is transmitted to the seated body as wholebody vibration is between $0.5 \mathrm{~Hz}$ to $80 \mathrm{~Hz}$ (ISO, 1997). Figure 1 shows the biocentric axes of the human body in seated and

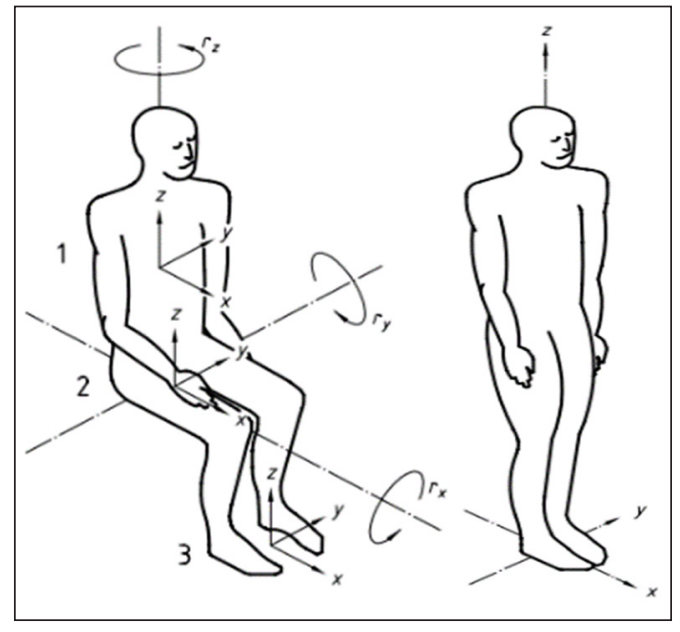

Figure 1. The biocentric axes of the human body in seated and standing positions (ISO, 1997) standing positions.

Therefore, the objective of this study is to study the effect of passenger orientation, operation time and BMI of passengers towards the whole body vibration in urban rail services.

\section{MATERIALS AND METHODS}

\section{Real-time Monitoring}

Real-time monitoring is a process of data collection from the actual real operation of the services. This study underwent real-time monitoring of the whole-body vibration in Kuala Lumpur urban rail. This line consists of 37 stations along the $45.1 \mathrm{~km}$ track with a driverless automatic system.

\section{Instruments}

This study used a triaxial accelerometer with a seat pad, and the Human Vibration Meter (HVM 100). Before the measurement was taken, the triaxial accelerometer was calibrated by using an Accelerometer Calibrator Kristler 8921. There are three (3) sets of triaxial accelerometers connected with three (3) individual HVM. The first triaxial accelerometer was attached to the seat where the subject sat. Meanwhile, the other one was attached to the floor under the feet of the other subject. Finally, the last set was attached to the floor under the seat to prevent anyone from step on it. All instruments used are shown in Figures 2(a) and 2(b); the measurement location inside the coach is shown in Figure 3. 


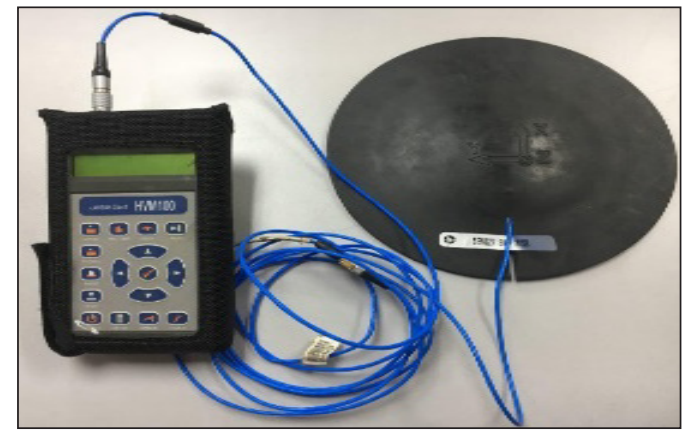

(a)

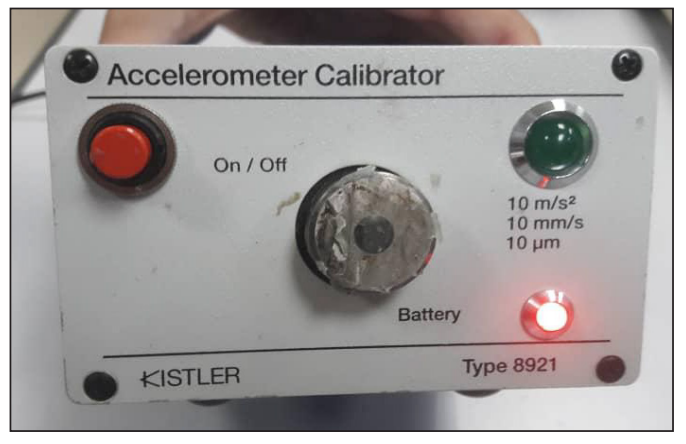

(b)

Figure 2. (a) HVM and Triaxial Accelerometer; and (b) Accelerometer Calibrator Kristler 8921

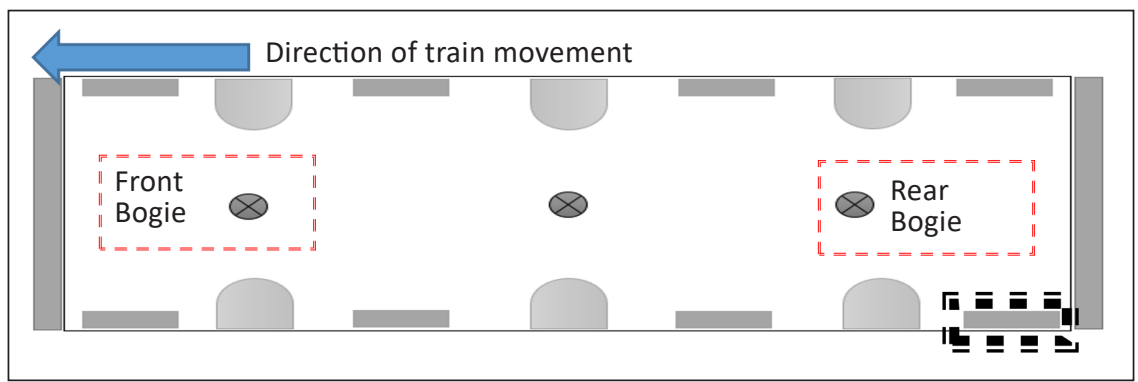

Figure 3. Locations of the measurements

\section{Body Mass Index (BMI)}

This study had chosen two subjects which represent BMI for normal and overweight. Details of the subject are shown in Table 1.
Table 1

Detail of subject

\begin{tabular}{ccccc}
\hline Subject & Height & Weight & BMI & Level \\
\hline A & $1.70 \mathrm{~m}$ & $65 \mathrm{~kg}$ & 22.5 & Normal \\
B & $1.84 \mathrm{~m}$ & $100 \mathrm{~kg}$ & 29.5 & Overweight \\
\hline
\end{tabular}

\section{Operation Time}

This study was conducted at two different operation times: peak and off-peak operation hours. Based on previous research, peak hours are between 7:00 am to 9:00 am and 4:30 pm to $6: 30 \mathrm{pm}$. Meanwhile, off-peak hours are outside the peak time (Wang et al., 2016).

\section{Orientation of Passenger}

Real-time monitoring began with installing two triaxial accelerometers on the floor and the passenger seat, based on ISO 2631-1. After that, both subjects would take their positions according to the procedure. For example, one subject sat on the seat pad while another stood on the seat pad, as seen in Figures 4(a) and 4(b). 


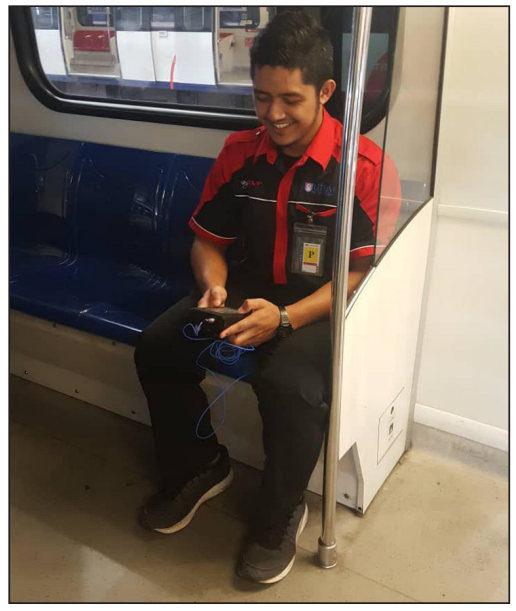

(a)

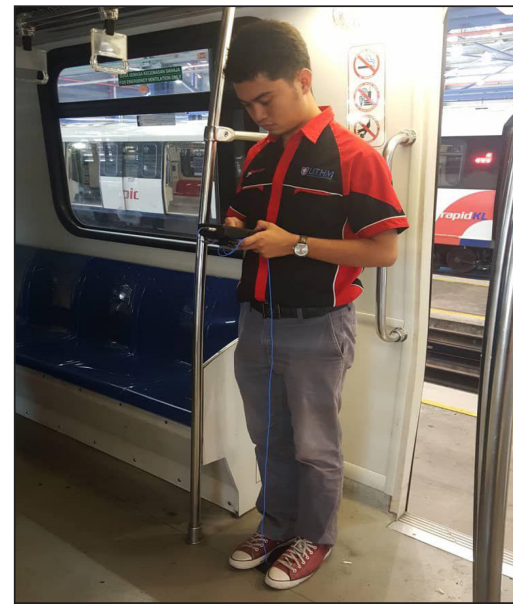

(b)

Figure 4. (a) Seating positions; and (b) Standing positions

\section{Full Factorial Experimental Design}

This study underwent $2^{3}$ full factorial experiment designs, as per showed in Table 2 .

The monitoring of the whole-body vibration took place along the route with, the region between each station labelled as a section. Table 3 summarises the labelling of each section.

Table 3

Sections of the urban rail route
Table 2

Design of experiment

\begin{tabular}{cccc}
\hline Case & $\begin{array}{c}\text { Operation } \\
\text { Time }\end{array}$ & Orientation & BMI \\
\hline 1 & Peak & Standing & Normal \\
& & Seating & Overweight \\
2 & Off-peak & Standing & Overweight \\
& & Seating & Normal \\
3 & Off-peak & Standing & Normal \\
& & Seating & Overweight \\
4 & Peak & Standing & Overweight \\
& & Seating & Normal \\
\hline
\end{tabular}

\begin{tabular}{cccccc}
\hline Station & Section & Station & Section & Station & Section \\
\hline Station A & Start & Station N & $\mathbf{1 3}$ & Station AA & $\mathbf{2 6}$ \\
Station B & $\mathbf{1}$ & Station O & $\mathbf{1 4}$ & Station BB & $\mathbf{2 7}$ \\
Station C & $\mathbf{2}$ & Station P & $\mathbf{1 5}$ & Station CC & $\mathbf{2 8}$ \\
Station D & $\mathbf{3}$ & Station Q & $\mathbf{1 6}$ & Station DD & $\mathbf{2 9}$ \\
Station E & $\mathbf{4}$ & Station R & $\mathbf{1 7}$ & Station EE & $\mathbf{3 0}$ \\
Station F & $\mathbf{5}$ & Station S & $\mathbf{1 8}$ & Station FF & $\mathbf{3 1}$ \\
Station G & $\mathbf{6}$ & Station T & $\mathbf{1 9}$ & Station GG & $\mathbf{3 2}$ \\
Station H & $\mathbf{7}$ & Station U & $\mathbf{2 0}$ & Station HH & $\mathbf{3 3}$ \\
Station I & $\mathbf{8}$ & Station V & $\mathbf{2 1}$ & Station II & $\mathbf{3 4}$ \\
Station J & $\mathbf{9}$ & Station W & $\mathbf{2 2}$ & Station JJ & $\mathbf{3 5}$ \\
Station K & $\mathbf{1 0}$ & Station X & $\mathbf{2 3}$ & Station KK & $\mathbf{3 6}$ \\
Station L & $\mathbf{1 1}$ & Station Y & $\mathbf{2 4}$ & & \\
Station M & $\mathbf{1 2}$ & Station Z & $\mathbf{2 5}$ & & \\
\hline
\end{tabular}




\section{Data Analysis}

Data analysis for this study involved calculating few parameters, which was done manually by following guidelines from ISO (1997).

This study measured the vibration on three (3) axes of the passenger and weighted acceleration that combines all the axes needed to calculate for further analysis. The formula used is shown in Equation 1. The weighting for the calculation is different between seating and vertical orientation, as

Table 4

Weighting for different orientation

\begin{tabular}{cccc}
\hline \multirow{2}{*}{ Orientation } & \multicolumn{3}{c}{ Weighting } \\
\cline { 2 - 4 } & X-axis & Y-axis & Z-axis \\
\hline Seating & 1.4 & 1.4 & 1.0 \\
Standing & 1.0 & 1.0 & 1.0 \\
\hline
\end{tabular}
shown in Table 4.

$$
a_{w}=\sqrt{\left(k a_{x}\right)^{2}+\left(k a_{y}\right)^{2}+\left(k a_{z}\right)^{2}}
$$

\section{Daily Vibration Exposure A (8)}

This study calculated the Daily Vibration Exposure A (8) to monitor vibration exposure to the passenger on the urban rail. The formula used to calculate $A(8)$ is shown in Equation 2.

$$
A(8)=a_{w}\left[\frac{T}{T_{o}}\right]^{\frac{1}{2}}
$$

\section{Statistical Analysis}

This study analyses the factorial design by using Minitab Software. There are 3 findings shall be presented from the statistical analysis of the full factorial design.

\section{Significant effect of the variables}

The result shall be presented by showing the Pareto Chart. The reference line drew on the chart indicates which factors that are tested in this study are significant.

\section{Level of statistically significant association between the variables}

This study developed 2 hypothesis statements which are listed below:

$\mathrm{H}_{0}=$ There is no statistically significant association between the variables.

$\mathrm{H}_{1}=$ There is a statistically significant association between the variables.

The decision to accept the hypothesis statement is based on the p-value of the analysis, where the significant level $(\alpha)$ is equivalent to $5 \%$ or 0.05 . 


\section{Level of Model Fits Data}

This study shall examine the goodness-of-fit statistic of the data in the model summary. The result shall be present in terms of the value of $\mathrm{R}^{2}$.

\section{RESULT}

This study presented the result from two processes: real-time monitoring and statistical analysis.

\section{Daily Vibration Exposure}

Figure 5 shows the result of daily vibration exposure for normal seated and standing passengers during peak hours. It is clearly shown that the value of the vibration exposure for the seated passenger is greater at most of the sections than the standing passenger. The greatest value of vibration exposure for the seating passenger is in Section $33\left(0.014 \mathrm{~ms}^{-2}\right)$; for the standing passenger is in Section $1\left(0.013 \mathrm{~ms}^{-2}\right)$.

Figure 6 shows the daily vibration exposure for normal seated and standing passengers during off-peak hours. It is clearly shown that the value of the vibration exposure for the

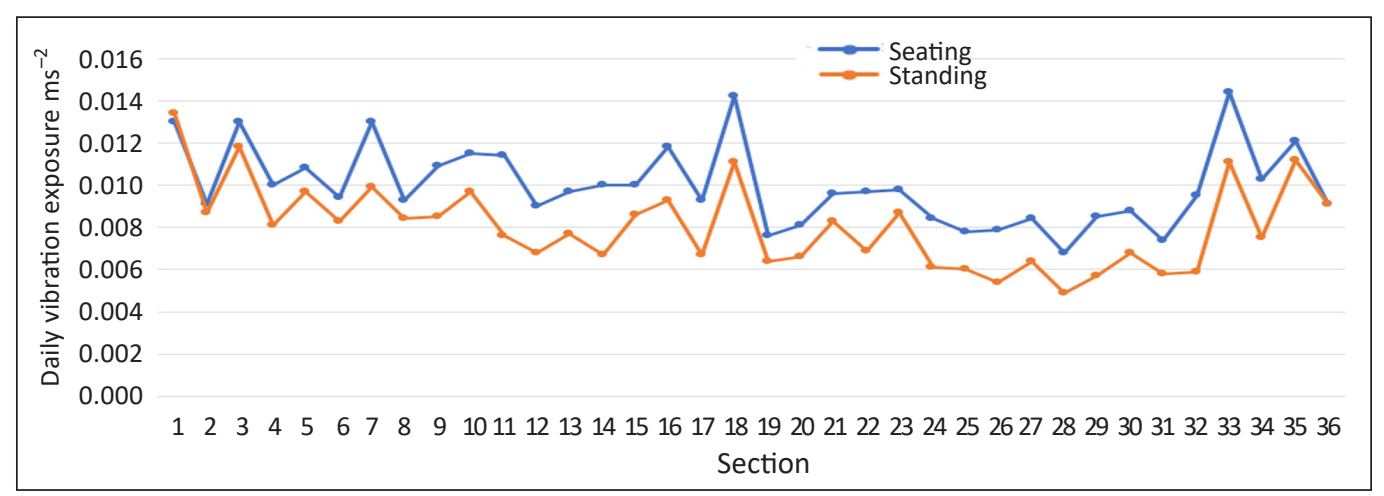

Figure 5. Daily vibration exposure for normal seated and standing passengers during peak hours

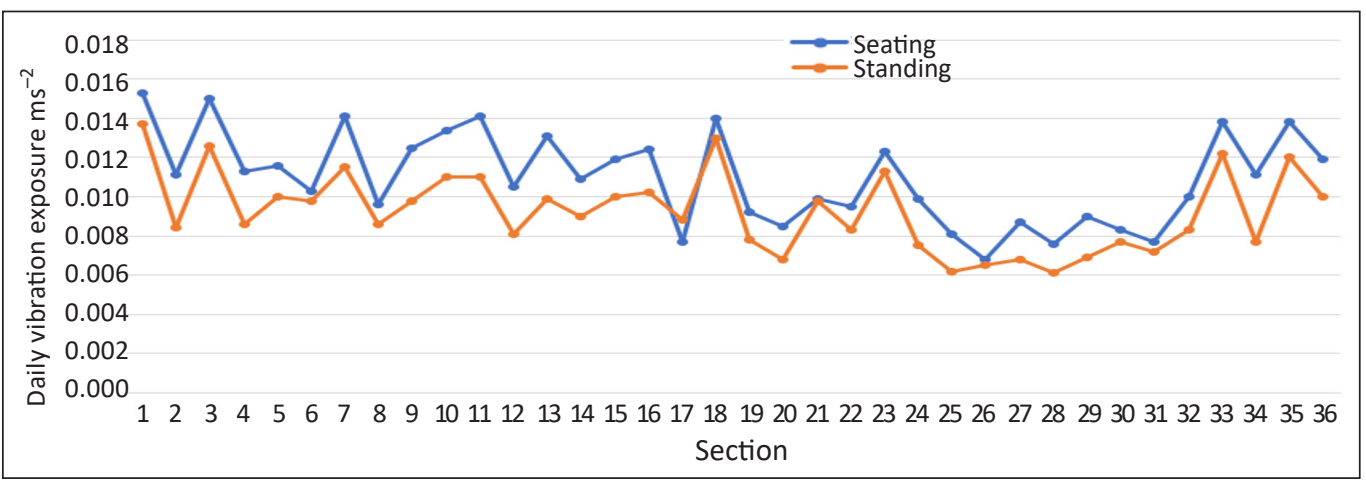

Figure 6. Daily vibration exposure for normal seating and standing passengers during off-peak time 
seated passenger is greater at 35 sections than the standing passenger. The greatest value of vibration exposure for the seated passenger is in Section $3\left(0.016 \mathrm{~ms}^{-2}\right)$, while for the highest value for standing passengers is in Section $1\left(0.013 \mathrm{~ms}^{-2}\right)$.

Figure 7 shows the daily vibration exposure for overweight seated and standing passengers during peak hours. There is only one section where the standing passenger was exposed to higher daily vibration than to the seated passenger; the value is higher for the seated passenger than the standing passenger in the other 35 sections. The greatest value of vibration exposure for the seated passenger is in Section $1\left(0.015 \mathrm{~ms}^{-2}\right)$ while, for the standing passenger is in Section $1\left(0.013 \mathrm{~ms}^{-2}\right)$.

Figure 8 shows the daily vibration exposure for overweight seated and standing passengers during off-peak hours. It is clearly shown that the value of the vibration exposure for the seated passenger is greater in most of the sections than the standing passenger. The greatest value of vibration exposure for the seated passenger is in Section $1\left(0.015 \mathrm{~ms}^{-2}\right)$, while for the standing passenger is in Section $1\left(0.014 \mathrm{~ms}^{-2}\right)$.

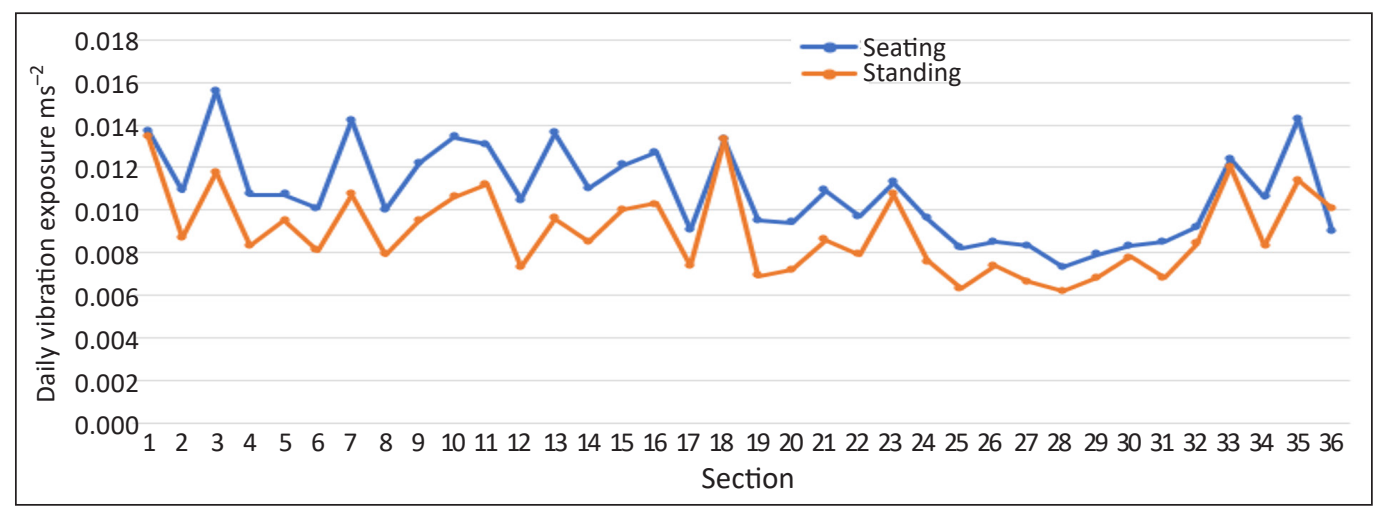

Figure 7. Daily vibration exposure for overweight seated and standing passengers during peak hours

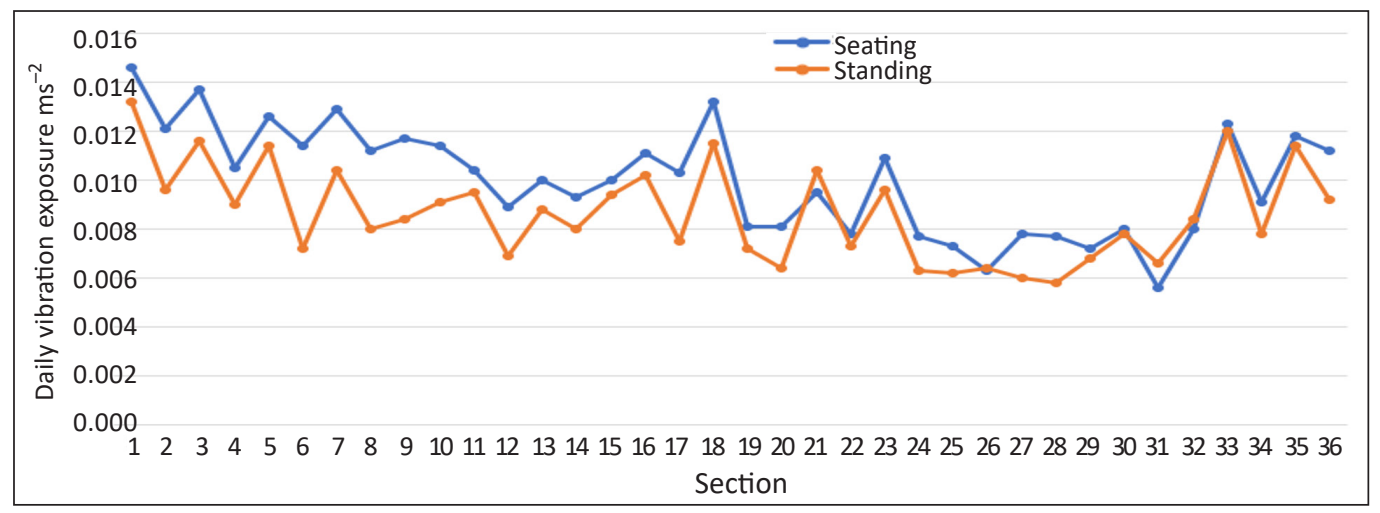

Figure 8. Daily vibration exposure for overweight seated and standing passengers during off-peak hours 


\section{Overall Daily Vibration Exposure}

Figure 9 shows normal passengers' overall daily vibration exposure for orientations (seated and standing) and both operation hours. During peak hours, normal seated passenger was exposed to $0.3686 \mathrm{~ms}^{-2}$ of vibration while standing passenger was exposed to $0.2965 \mathrm{~ms}^{-2}$. Besides that, during off-peak hours, the seated passenger was exposed to $0.4000 \mathrm{~ms}^{-2}$ while the standing passenger was exposed to $0.3326 \mathrm{~ms}^{-2}$. Thus, it shows that seated passenger was exposed to greater vibration than standing passenger for both operation hours.

Figure 10 shows the overall daily vibration exposure for overweight passenger for both orientation and operation hours. While seated, the overweight passengers was exposed to about $0.3706 \mathrm{~ms}^{-2}$ of vibration during peak hours and $0.4063 \mathrm{~ms}^{-2}$ for the same orientation during off-peak hours. While standing, the overweight passenger was exposed to 0.3187 $\mathrm{ms}^{-2}$ of whole-body vibration during peak hours than $0.3409 \mathrm{~ms}^{-2}$ during off-peak hours. It clearly shows that overweight passengers are exposed to greater whole-body vibration while seated than standing and experience greater exposure during off-peak hours than peak hours.

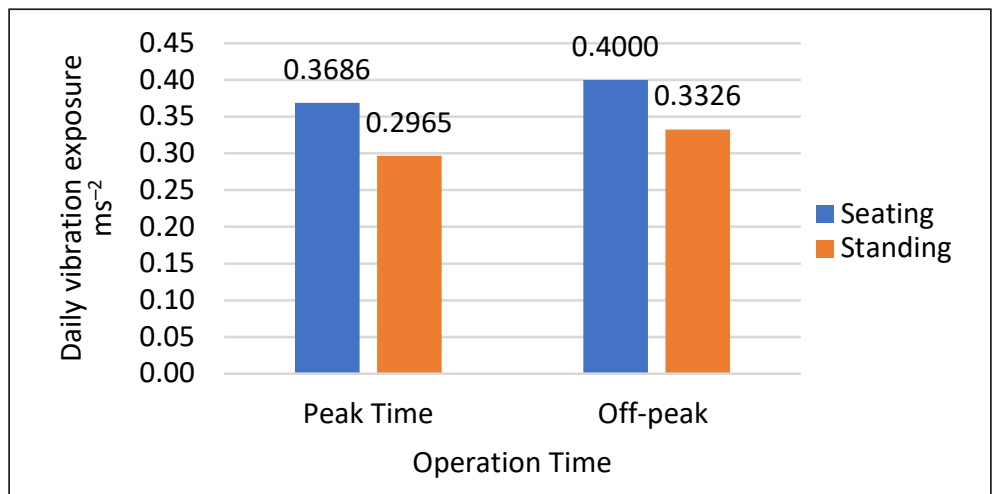

Figure 9. Overall A (8) for normal passenger

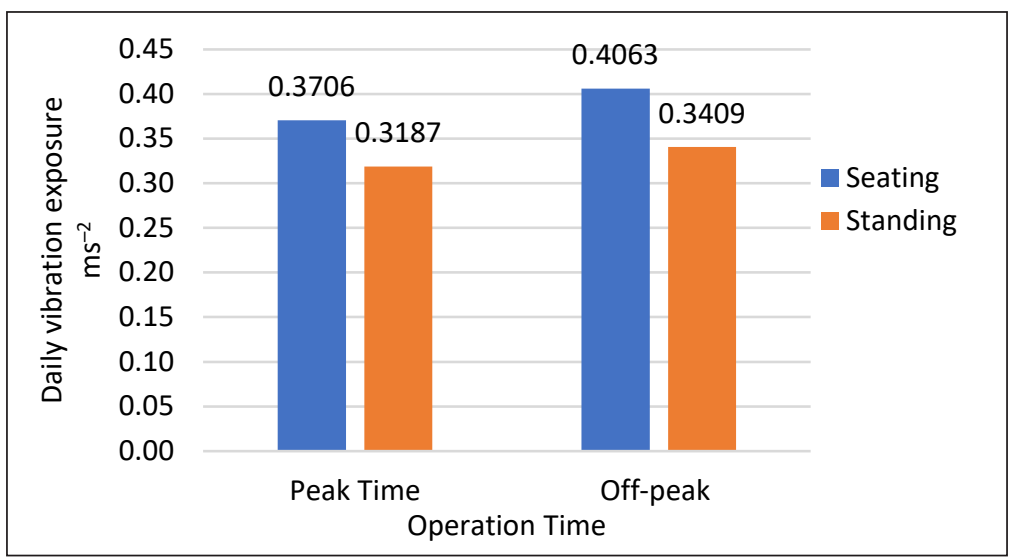

Figure 10. Overall A (8) for overweight passenger 
Figure 11 shows the result of overall daily vibration exposure for the seated passenger. The result shows that the normal seated passenger was exposed to $0.3686 \mathrm{~ms}^{-2}$ of daily vibration exposure during peak hours than the seated overweight seated, $0.3706 \mathrm{~ms}^{-2}$. Meanwhile, during off-peak hours, the normal seated passenger was exposed to 0.4000 $\mathrm{ms}^{-2}$ and the overweight seated passenger was exposed to $0.4063 \mathrm{~ms}^{-2}$. Therefore, it can be concluded that the overweight passenger was exposed to greater daily vibration exposure than the normal seating passenger during both operation hours.

Figure 12 shows the result of overall daily vibration exposure for the standing passenger. During peak hours, the normal standing passenger was exposed to $0.2965 \mathrm{~ms}^{-2}$ of daily vibration exposure, and the overweight standing passenger was exposed to 0.3187 $\mathrm{ms}^{-2}$. Meanwhile, during off-peak hours, the normal standing passenger was exposed to $0.3326 \mathrm{~ms}^{-2}$ and the overweight seated passenger was exposed to $0.3409 \mathrm{~ms}^{-2}$. Therefore, it can be concluded that the overweight passenger tends to receive a greater daily vibration exposure than the normal seated passenger during both operation hours.

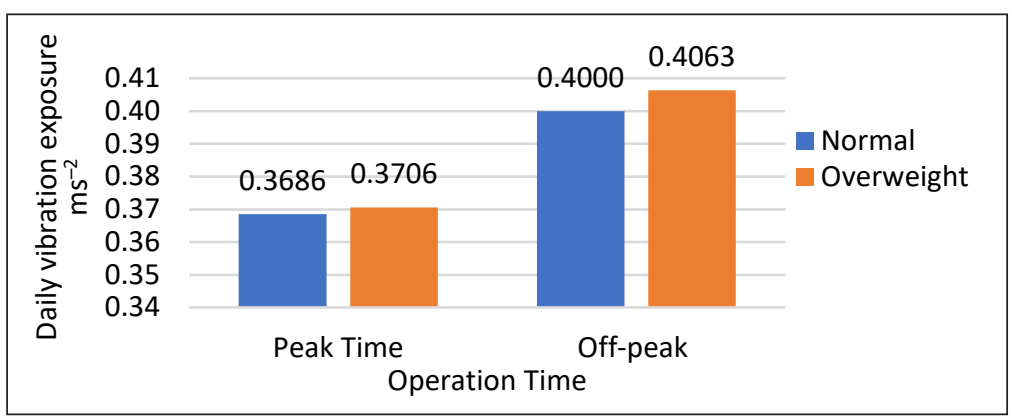

Figure 11. Overall A (8) for seating passenger

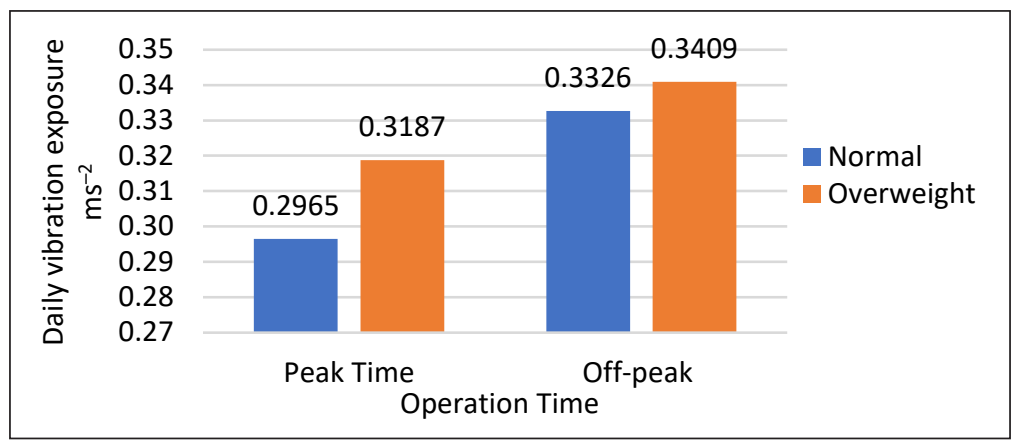

Figure 12. Overall A (8) for standing passenger

\section{$2^{3}$ Full Factorial Design}

Significant Effect of the Variables. Figure 13 shows the Pareto Chart from the $2^{3}$ full factorial design analysis. The chart shows that all three (3) factors are statistically significant $(\alpha=0.05)$. The chart also shows that the largest effect on the passenger's 


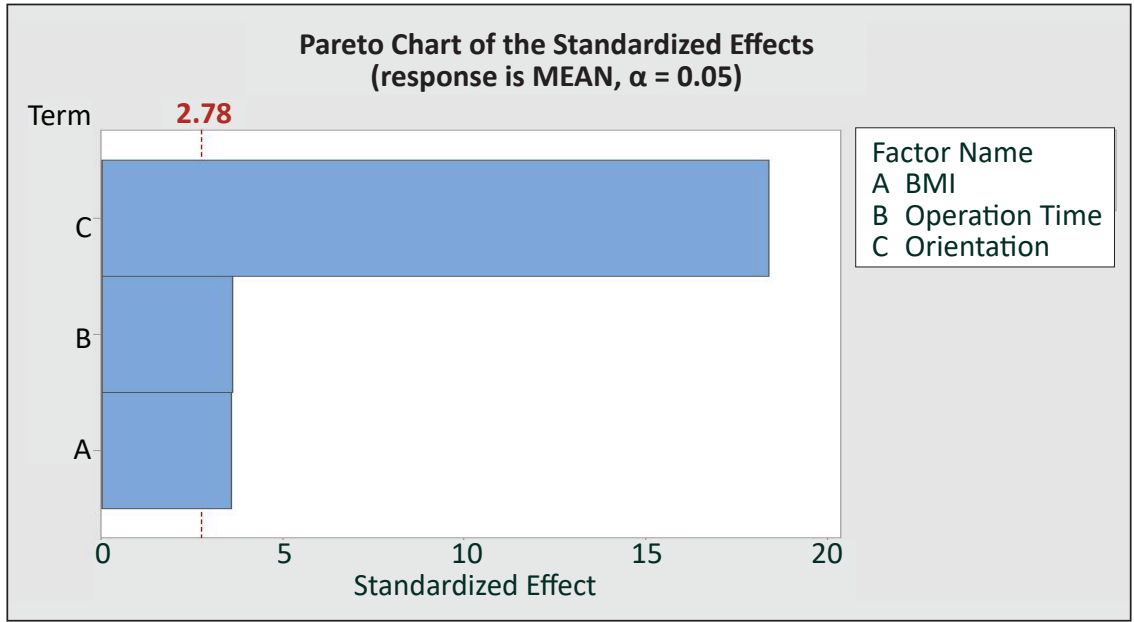

Figure 13. Pareto Chart

whole body vibration exposure is the body mass index, followed by operation time. The orientation of the passenger is the smallest because it extends the least in the Pareto Chart.

Level of Statistically Significant Association between the Variables. There are three (3) hypothesis statements that are tested in this full factorial design analysis which are:

\section{Body Mass Index (BMI)}

$\mathrm{H}_{0}=$ There is no statistically significant association between Body Mass Index (BMI), Operation Time and Orientation of Passenger.

$\mathrm{H}_{1}=$ There is a statistically significant association between Body Mass Index (BMI), Operation Time and Orientation of Passenger.

\section{Operation Time}

$\mathrm{H}_{0}=$ There is no statistically significant association between Operation time, Body Mass Index (BMI) and Orientation of Passenger.

$\mathrm{H}_{1}=$ There is a statistically significant association between Operation time, Body Mass Index (BMI) and Orientation of Passenger.

\section{Orientation of Passenger}

$\mathrm{H}_{0}=$ There is no statistically significant association between Orientation of Passenger, Body Mass Index (BMI) and Operation Time.

$\mathrm{H}_{1}=$ There is a statistically significant association between Orientation of Passenger, Body Mass Index (BMI) and Operation Time. 
Table 5

Coded coefficients

\begin{tabular}{lcccccc}
\hline \multicolumn{1}{c}{ Term } & Effect & Coef & SE Coef & T-Value & P-Value & VIF \\
\hline Constant & & 0.37944 & 0.00157 & 241.63 & 0.000 & \\
BMI & 0.01125 & 0.00563 & 0.00157 & 3.58 & 0.023 & 1.00 \\
Operation Time & 0.01136 & 0.00568 & 0.00157 & 3.62 & 0.022 & 1.00 \\
Orientation & -0.05776 & -0.02888 & 0.00157 & -18.39 & 0.000 & 1.00 \\
\hline
\end{tabular}

Table 5 shows that the coded coefficients from the Minitab result. The result shows that the main effect of BMI, Operation and Orientation of passengers are statistically significant which are the value of $\mathrm{p}$-value are less than $\alpha=0.05$. Therefore, the decision for the hypothesis statement is $\mathrm{H}_{0}$ is rejected for all the variables where there is a statistically significant association between Body Mass Index (BMI), Operation Time and Orientation of Passenger.

Level of Model Fits Data. In these results in Table 6, the value of $\mathrm{R}^{2}$ is $98.91 \%$, indicating that the model provides a good fit for the data.

Table 6

Model summary

\begin{tabular}{cccc}
\hline S & R-sq & R-sq(adj) & R-sq(Pred) \\
\hline 0.0044417 & $98.91 \%$ & $98.10 \%$ & $95.65 \%$ \\
\hline
\end{tabular}

\section{DISCUSSION}

\section{Real-time Monitoring}

Orientation of Passenger. For the normal passenger, it is found that during peak hours, the daily vibration exposure for the seated passenger is $0.3686 \mathrm{~ms}^{-2}$ while the standing passenger was exposed to $0.2965 \mathrm{~ms}^{-2}$. It shows that the seated passenger was exposed to $24 \%$ more daily vibration than the standing passenger during peak hours. Besides that, during off-peak hours, the seated passenger was exposed to $0.4 \mathrm{~ms}^{-2}$ while the standing passenger was exposed to $0.3326 \mathrm{~ms}^{-2}$. It shows that the seated passenger was exposed to $20 \%$ greater daily vibration than the seated passenger. It is due to greater surface exposure toward the seated passenger than the standing passenger.

For the overweight passenger, it is found that during peak hours, the daily vibration exposure for the seated passenger is $0.3706 \mathrm{~ms}^{-2}$ while the standing passenger was exposed to $0.3187 \mathrm{~ms}^{-2}$. Therefore, it shows that the seated passenger was exposed to $16 \%$ greater daily vibration than the standing passenger during peak hours. Besides that, during offpeak hours, the seated passenger was exposed to $0.4063 \mathrm{~ms}^{-2}$ while the standing passenger was exposed to $0.3409 \mathrm{~ms}^{-2}$. Thus, it shows that the seated passenger was exposed to $19 \%$ greater daily vibration than the seated passenger.

From both results, it was found that the seated passenger was exposed to greater daily vibration than the standing passenger. This result corresponds with previous research, where 
the researcher found that the seated passenger gained higher vibration than the standing passenger (Hasnan et al., 2018). This phenomenon is caused by a difference in the area of contact between both orientations. A seated passenger has fewer body parts exposed to the vibrating surface, such as the buttock, feet and back. Meanwhile, the passenger in a vertical orientation only has one area of contact: their feet (Kumar \& Saran, 2014).

\section{Operation Time}

For the normal weight passenger, it was found that in the seated orientation, the daily vibration exposure during peak hours is $0.3686 \mathrm{~ms}^{-2}$ while during off-peak hours is $0.4 \mathrm{~ms}^{-2}$. Therefore, it shows that the seated orientation caused $8 \%$ greater daily vibration exposure during off-peak hours than peak hours. Besides that, the standing passenger was exposed to $0.2965 \mathrm{~ms}^{-2}$ during peak hours and $0.3326 \mathrm{~ms}^{-2}$ during off-peak hours. Therefore, it shows that the vertical orientation caused $12 \%$ greater daily vibration exposure during off-peak hours than peak hours.

For the overweight passenger, it was found that in the seated orientation, the daily vibration exposure during peak hours is $0.3706 \mathrm{~ms}^{-2}$ and $0.4063 \mathrm{~ms}^{-2}$ during off-peak hours. It shows that the seated orientation causes $9 \%$ greater daily vibration exposure during offpeak hours than peak hours. Besides that, in the vertical orientation, the passenger was exposed to $0.3187 \mathrm{~ms}^{-2}$ of vibration during peak hours and $0.3409 \mathrm{~ms}^{-2}$ during off-peak hours. It shows that the vertical orientation causes $7 \%$ greater daily vibration exposure during off-peak hours than peak hours.

Therefore, from both results, it was found that the passenger tends to be exposed to greater daily vibration during off-peak hours than peak hours in both orientations. It is due to the difference in the overall mass of the train between both operation hours. The overall mass of the train is greater during peak hours than during off-peak hours. Therefore, during peak hours, the numbers of passengers board the train were higher than during off-peak hours. When the mass decreases, the vibration will increase (Tuladhar et al., 2018). It is why the train's vibration transmission rate is higher during off-peak hours than during peak hours. Other than that, the speed of the train differs during both operation hours. The train arrives every three minutes during peak hours and every eight minutes during off-peak hours. However, the number of operating trains is the same during both operation hours. It shows that the train travels slower during off-peak hours than peak hours. When the train speed decreases, the vibration will increase (Karakasis et al., 2005).

\section{Body Mass Index of Passenger}

For the seated passenger, it was found that the normal weight passenger was exposed to $0.3686 \mathrm{~ms}^{-2}$ of vibration during peak hours, while the overweight passenger was exposed to $0.3706 \mathrm{~ms}^{-2}$. However, during off-peak hours, the normal weight passenger was exposed 
to $0.4000 \mathrm{~ms}^{-2}$ of vibration, and the overweight passenger was exposed to $0.4063 \mathrm{~ms}^{-2}$. Thus, it shows that the overweight passenger experienced slightly greater exposure to daily vibration than normal passengers during both operation hours.

In the vertical orientation, the daily vibration exposure during peak hours for the normal weight passenger was $0.2965 \mathrm{~ms}^{-2}$ while the overweight passenger was $0.3187 \mathrm{~ms}^{-2}$. It shows that the overweight passenger was exposed to $7 \%$ greater daily vibration during peak hours than the normal weight passenger. Besides that, during off-peak hours, the normal passenger was exposed to $0.3326 \mathrm{~ms}^{-2}$ of vibration, and the overweight passenger was exposed to $0.3409 \mathrm{~ms}^{-2}$. Therefore, it shows that the overweight passenger was exposed to slightly greater daily vibration than the normal passenger during both operation hours.

\section{CONCLUSION}

This study concludes that passenger orientation has a significant effect on daily vibration exposure. In addition, the seated passenger was exposed to greater whole-body vibration than the standing passenger. Operation hours have a significant effect on the daily vibration exposure. Daily vibration exposure was greater during off-peak hours than during peak hours. Lastly, the overweight passenger experienced greater whole-body vibration than the normal weight passenger. All the variables are statistically significant and shall affect the value of whole-body vibration of the urban rail passenger.

\section{ACKNOWLEDGEMENT}

The authors were supported by the Post Graduate Research Grant (GPPS) by Universiti Tun Hussein Onn Malaysia. The authors would also like to thank Rapid Rail Sdn Bhd and Prasarana Malaysia Berhad for their contribution and participation in this study. The authors declare that there is no conflict of interest.

\section{REFERENCES}

Azlis-Sani, J., Zaid, M. F., Yahya, M. N., Ismail, S. M. S. S. M., Ahmad Tajedi, N. A., Aziz, R. A., \& Zein, R. M. (2015). Evaluation of whole body vibration and back pain problem among light rapid transit (LRT) Drivers. Applied Mechanics and Materials, 773-774, 845-849. https://doi.org/10.4028/www.scientific. net/amm.773-774.845

Dumitriu, M. (2013). Evaluation of the comfort index in railway vehicles depending on the vertical suspension features. Annals of Faculty Engineering Hunedoara, 11(4), 23-32.

Fateh, A., Hejazi, F., Ramanathan, R. A., \& Jaffar, M. S. (2016). Seismic response of a light rail transit station equipped with braced viscous damper. Pertanika Journal of Science and Technology, 24(2), 273-283.

Gągorowski, A. (2010). Simulation study on stiffness of suspension seat in the aspect of the vibration assessment affecting a vehicle driver. Logistics and Transport, 11, 55-62. 
Griffin, M. J., \& Erdreich, J. (1991). Handbook of Human Vibration. The Journal of the Acoustical Society of America, 90 (4), Article 2213. https://doi.org/10.1121/1.401606

Hasnan, K., Bakhsh, Q., Ahmed, A., Ali, D., \& Jamali, A. R. (2018). Analysis of WBV on standing and seated passengers during off-peak operation in KL monorail. IOP Conference Series: Materials Science and Engineering, 324(1), 2-7. https://doi.org/10.1088/1757-899X/324/1/012003

Ismail, A. R., Nuawi, M. Z., How, C. W., Kamaruddin, N. F., Nor, M. J. M., \& Makhtar, N. K. (2010). Whole body vibration exposure to train passenger. American Journal of Applied Sciences, 7(3), 352-359. https:// doi.org/10.3844/ajassp.2010.352.359

ISO, I. (1997). 2631-1: Mechanical vibration and shock-evaluation of human exposure to whole-body vibrationPart 1: General requirements. ISO.

Karakasis, K., Skarlatos, D., \& Zakinthinos, T. (2005). A factorial analysis for the determination of an optimal train speed with a desired ride comfort. Applied Acoustics, 66(10), 1121-1134. https://doi.org/10.1016/j. apacoust.2005.02.006

Kim, Y. G., Choi, S., Kim, S. W., Kim, Y. M., \& Park, T. W. (2009). An experimental study on the ride comfort of the Korean high-speed train. Experimental Techniques, 33(6), 30-37. https://doi.org/10.1111/j.17471567.2008.00419.x

Kumar, V., \& Saran, V. H. (2014). Influence of reading format on reading activity under uniaxial whole body vibration. International Journal of Industrial Ergonomics, 44(4), 520-527. https://doi.org/10.1016/j. ergon.2014.05.004

Kumara, V., Saranb, V. H., \& Guruguntla, V. (2013, December 18-20). Study of vibration dose value and discomfort due to whole body vibration exposure for a two wheeler drive. In Proceedings of the 1st International and 16th National Conference on Machines and Mechanisms (iNaCoMM2013) (pp. 947952). IIT Roorkee, India.

Mohajer, N., Abdi, H., Nahavandi, S., \& Nelson, K. (2017). Directional and sectional ride comfort estimation using an integrated human biomechanical-seat foam model. Journal of Sound and Vibration, 403, 38-58. https://doi.org/10.1016/j.jsv.2017.05.019

Mortimer, M., Wiktorin, C., Pernold, G., Svensson, H., \& Vingård, E. (2001). Sports activities, body weight and smoking in relation to low-back pain: A population-based case-referent study. Scandinavian Journal of Medicine and Science in Sports, 11(3), 178-184. https://doi.org/10.1046/j.1524-4725.2001. 110308.x

Munawir, T. I. T., Samah, A. A. A., Rosle, M. A. A., Azlis-Sani, J., Hasnan, K., Sabri, S. M., Ismail, S. M., Yunos, M. N. A. M., \& Bin, T. Y. (2017). A comparison study on the assessment of ride comfort for LRT passengers. In IOP Conference Series: Materials Science and Engineering (Vol. 226, No. 1, p. 012039). IOP Publishing.https://doi.org/10.1088/1757-899X/226/1/012039

Nuawi, M. Z., Ismail, A. R., Nor, M. J. M., \& Rahman, M. M. (2011). Comparative study of whole-body vibration exposure between train and car passengers: A case study in malaysia. International Journal of Automotive and Mechanical Engineering, 4, 490-503.

Park, M., Fukuda, T., Kim, T., \& Maeda, S. (2013). Health risk evaluation of whole-body vibration by ISO 2631-5 and ISO 2631-1 for operators of agricultural tractors and recreational vehicles. Industrial Health, 51(3), 364-370. https://doi.org/10.2486/indhealth.2012-0045 
Pradhan, S., Samantaray, A. K., \& Bhattarcharyya, R. (2017). Evaluation of ride comfort in a railway passenger vehicle with integrated vehicle and human body bond graph model. In ASME International Mechanical Engineering Congress and Exposition (Vol. 58479, p. V012T16A013). American Society of Mechanical Engineers. https://doi.org/10.1115/IMECE2017-71288

Schwarze, S., Notbohm, G., Dupuis, H., \& Härtung, E. (1998). Dose-response relationships between wholebody vibration and lumbar disk disease - A field study on 388 drivers of different vehicles. Journal of Sound and Vibration, 215(4), 613-628. https://doi.org/10.1006/jsvi.1998.1602

Smith, D. L., Chang, J., Cohen, D., Foley, J., \& Glassco, R. (2005, November 6-10). A simulation approach for evaluating the relative safety impact of driver distraction during secondary tasks. In 12th World Congress on ITS (pp. 1-12). San Francisco, California.

Tuladhar, S. R., Khomchuk, P., \& Sivananthan, S. (2018). Estimating passenger loading on train cars using accelerometer. ArXiv Publishing.

Wang, X., Fan, T., Li, W., Yu, R., Bullock, D., Wu, B., \& Tremont, P. (2016). Speed variation during peak and off-peak hours on urban arterials in Shanghai. Transportation Research Part C: Emerging Technologies, 67, 84-94. https://doi.org/10.1016/j.trc.2016.02.005

Zhou, C., Dai, P., Wang, F., \& Zhang, Z. (2016). Predicting the passenger demand on bus services for mobile users. Pervasive and Mobile Computing, 25(2013), 48-66. https://doi.org/10.1016/j.pmcj.2015.10.003 